\title{
The Soybean GmN6L Gene Encodes a Late Nodulin Expressed in the Infected Zone of Nitrogen-Fixing Nodules
}

\author{
Ben Trevaskis, Maren Wandrey, Gillian Colebatch, and Michael K. Udvardi \\ Max Planck Institute of Molecular Plant Physiology, Am Mühlenberg 1, 14476 Golm, Germany
}

Submitted 3 December 2001. Accepted 9 March 2002.

\begin{abstract}
Previously, we determined the N-terminal amino acid sequences of a number of putative peribacteroid membrane proteins from soybean. Here, we report the cloning of a gene, GmN6L, that encodes one of these proteins. The protein encoded by $G m N 6 L$ is similar in sequence to MtN6, an early nodulin expressed in Medicago truncatula roots in response to infection by Sinorhizobium meliloti. The GmN6L gene was strongly expressed in mature nodules but not in other plant organs. GmN6L protein was first detected 2 weeks after inoculation with Bradyrhizobium japonicum and was limited to the infected zone of nodules. GmN6L protein was found in symbiosomes isolated from mature soybean nodules, both as a soluble protein and as a peripheral membrane protein bound to the peribacteroid membrane. These data indicate that GmN6L is a late nodulin, which is not involved in the infection process. Homology between GmN6L and FluG, a protein involved in signaling in Aspergillus nidulans, suggests that GmN6L may play a role in communication between the host and microsymbionts during symbiotic nitrogen fixation.
\end{abstract}

Additional keyword: symbiosis.

Although plants are unable to fix atmospheric $\mathrm{N}_{2}$ directly, some plant species are able to access this nitrogen through symbiotic interactions with nitrogen-fixing microorganisms. The best understood examples of such symbioses are those that occur between legumes and bacteria of the Rhizobiaceae family. The legume-rhizobium symbiosis is initiated by signal exchange between the plant root and soil-dwelling rhizobia, which leads to bacterial attachment to root hair cells, invasion of root tissue via an invagination of the root hair cell wall called the infection thread, entry of rhizobia into root cortical cells, and concomitant development of a specialized organ known as the nodule (Stougaard 2000). Entry of rhizobia into cortical cells occurs via endocytosis of the host cell membrane. This results in the formation of a unique plant membrane, the peribacteroid membrane (PBM), which surrounds the rhizobia and delimits a novel organelle called the symbiosome. Symbiosomes multiply, as the rhizobia grow and divide, until host cells are packed with thousands of such organelles, each containing one or a few bacteria. The changing physiological conditions within developing nodules eventually trigger differentiation of rhizobia into bacteroids, the nitrogen-fixing form of the bacteria.

Corresponding author: Michael Udvardi; Telephone: +49 331567 8149; Fax: +49 331567 8250; E-mail: Udvardi@ mpimp-golm.mpg.de

Nucleotide sequence data of $G m N 6 L$ are available in the GenBank database under the accession number AF43718.
Bacteroids export fixed nitrogen to the plant cytoplasm in the form of ammonia (Bergersen and Turner 1990) and possibly also alanine (Allaway et al. 2000). In return, the bacteroids receive carbon compounds, mainly dicarboxylates, and other nutrients from the plant (Udvardi and Day 1997). Exchange of metabolites between the symbionts is regulated by the PBM.

There are many plant genes that are expressed only in nodules or inoculated root tissue. These so-called nodulin genes are likely to encode proteins that are required for the development and maintenance of nitrogen-fixing nodules. Nodulins have been divided into two classes based on gene expression patterns. Early nodulins are expressed soon after contact with rhizobia and may be necessary for infection and the initial stages of nodule development. Late nodulins are expressed in mature nodules and may play important roles in the metabolism, maintenance, or senescence of nodules (Stougaard 2000). One early nodulin gene cloned from Medicago truncatula was designated MtN6 (Gamas et al. 1996). This gene was induced by rhizobial infection, with maximal expression observed $48 \mathrm{~h}$ after infection. MtN6 gene expression was localized to plant cells adjacent to preinfection and infection threads, which surround the bacteria as they penetrate plant root tissue (Mathis et al. 1999). Although the precise function of MtN6 is not clear, it has been suggested that the protein could play a role in the infection process (Mathis et al. 1999).

Previously, we used a proteomics approach to obtain N-terminal sequences of a number of putative PBM proteins (Panter et al. 2000). Among the partially sequenced proteins were two closely related proteins designated PBM19 and PBM65 (Panter et al. 2000). These proteins exhibited similar masses but different isoelectric points on two-dimensional gels, which also indicated that PBM19 was present at a higher concentration than PBM65 in PBM fractions. The peptide sequences of PBM19 and PBM65 showed no strong homology to any known plant proteins at the time of identification (Panter et al. 2000). By performing polymerase chain reaction (PCR) with degenerate primers, we were able to isolate a gene that encodes a protein containing the PBM19 N-terminal peptide sequence. This protein is homologous to the early nodulin MtN6 from $M$. truncatula. However, unlike MtN6, the soybean protein, called GmN6L, is a late nodulin. Here, we describe the molecular and cellular biology of GmN6L, a novel nodulin in soybean.

\section{RESULTS}

Cloning of the soybean GmN6L cDNA.

To clone the gene encoding PBM19, degenerate oligonucleotide primers were designed to all codons that could potentially encode the sequenced part of the protein. These primers were used with a universal reverse primer (URP) to amplify by $3^{\prime}$ RACE (rapid amplification of cDNA ends) a fragment from 
nodule first-strand cDNA. 5'-RACE was then used to obtain the full-length cDNA sequence (GenBank accession no. AF434718). The cDNA has a single open reading frame for a predicted protein of 432 amino acids, which includes a stretch of 19 amino acids that are identical to the PBM19 peptide sequence (Panter et al. 2000), supporting the idea that this gene encodes the PBM19 protein.

BlastA (Altschul et al. 1990) and FastA (Pearson and Lipman 1988) searches of translated plant nucleic acid sequence databases were performed with the predicted protein sequence of this cDNA. Strong homology to the predicted amino acid sequence of MtN6 from M. truncatula was found. Significant homology to a translated genomic sequence from Arabidopsis thaliana (CAB64221.1) and translated expressed sequence tag (EST) sequences from a range of plant species was also found. Given the strong homology between this sequence and MtN6, we named the gene Glycine max Nodulin 6like $(G m N 6 L)$. The predicted protein sequence of GmN6L also showed homology to the N-terminal domain of FluG, a twodomain protein from Aspergillus nidulans, as did the MtN6 protein (Gamas et al. 1996). An alignment of the predicted amino acid sequences of MtN6, GmN6L, and FluG is shown (Fig. 1).

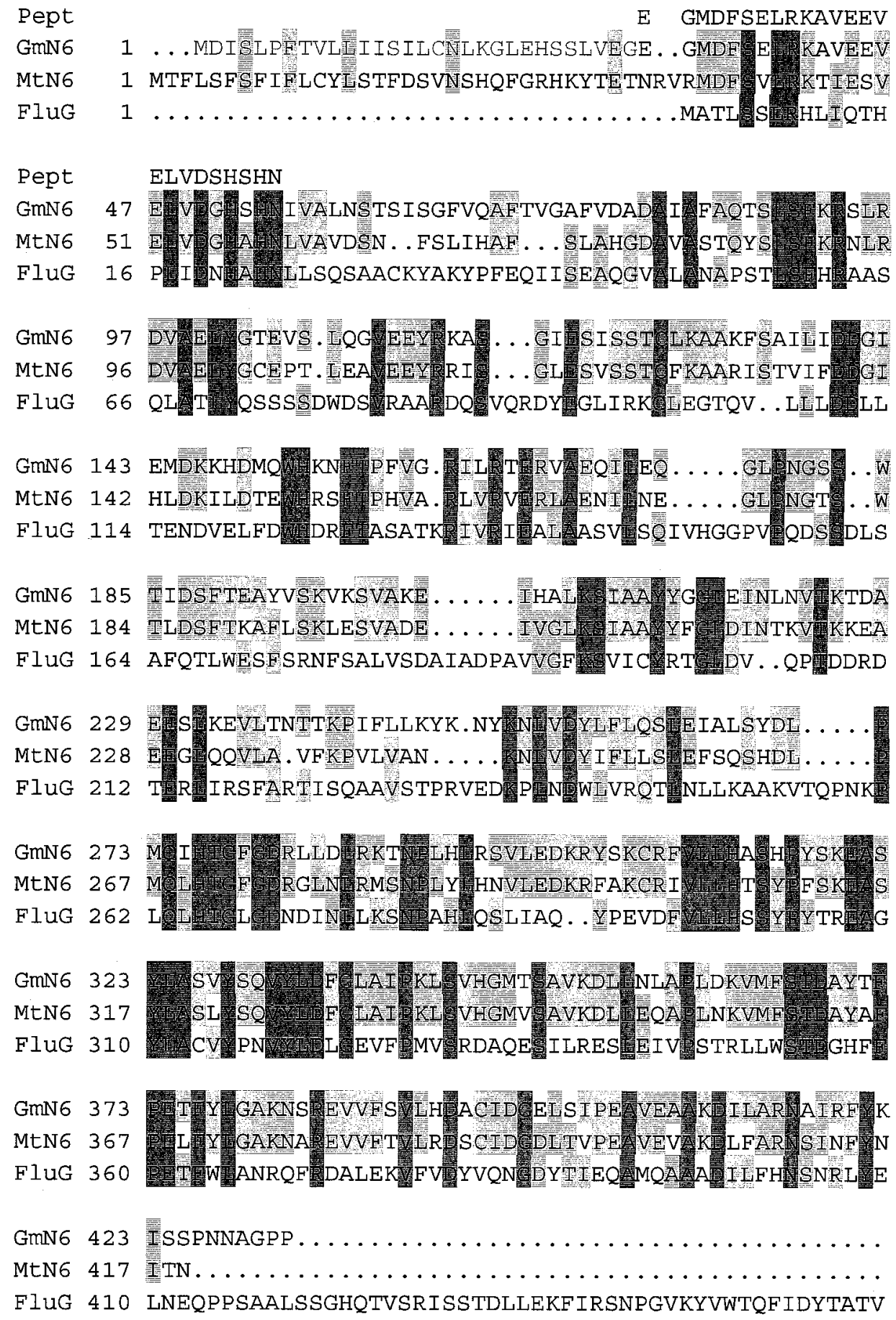

Fig. 1. Alignment of GmN6L, MtN6, and FluG amino acid sequences. GmN6L (GenBank accession no. AF434718), MtN6 (GenBank accession no. Y18225), and amino acids 1 to 460 of FluG (GenBank accession no. L27817) were aligned by using the Pileup function in GCG (Genetics Computing Group, Madison, WI, U.S.A.). Residues identical in two of three proteins are highlighted in light grey, and those identical in all three are highlighted in dark grey. The hydrophobic leader sequence of GmN6L is underlined. The PBM19 peptide (Pept) sequence is also included in this alignment. 
Southern blots of restriction enzyme-digested soybean genomic DNA were probed at high stringency with the 3 '-untranslated region (UTR) of GmN6L (data not shown). Two hybridizing bands were detected for each enzyme. As none of the four enzymes used to digest the genomic DNA were able to cut within the sequence of the probe, it appeared that there were two copies of the $G m N 6 L$ gene in the soybean genome. We searched for homologues of $G m N 6 L$ in the soybean EST database of GenBank and identified two ESTs derived from the GmN6L gene (GenBank accession nos. A1988552 and A1988327). However, no homologues were found amongst the more than 190,000 ESTs.

\section{GmN6L is expressed in mature nodules.}

We analyzed $G m N 6 L$ gene expression in a range of plant organs using RNA gel blots. Strong expression of $G m N 6 L$ was detected in total RNA from nodules harvested from 4-week-old soybean plants (Fig. 2). No signal was detected in aboveground tissues or in uninoculated roots. Expression of GmN6L during the early stages of nodule development was also analyzed. RNA was harvested from roots at a number of time points following inoculation with rhizobia and RNA gel blots performed. The GmN6L transcript was first detected in the root systems 2 weeks after inoculation (Fig. 3). At this stage, small nodules had appeared.

For a more sensitive assay of GmN6L gene expression during the early stages of nodulation, we used real time reversetranscriptase (RT)-PCR. The levels of transcript for ubiquitin, a constitutively expressed gene, were also analyzed for comparison. As expected, the levels of ubiquitin transcript were approximately equivalent between samples when equal amounts of RNA were used as starting material (Table 1). Expression of GmN6L was detected in uninoculated roots by real time RTPCR, in contrast to the Northern blots, but the expression level was very low as indicated by the high $\mathrm{C}_{\mathrm{T}}$ (threshold cycle) value obtained (Table 1). Strong induction of GmN6L gene expression was not observed until 2 weeks postinoculation, in accordance with the observations made with RNA gel blots (Table 1; Fig. 3).

The analysis of GmN6L expression was extended to the protein level. Western blots were performed with an anti-N6L antibody to examine the levels of the GmN6L protein in various tissues. A band of approximately $50 \mathrm{kDa}$, the predicted size of

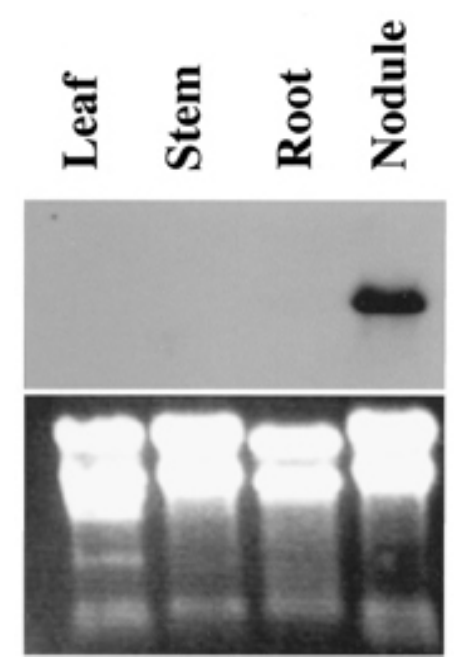

Fig. 2. $G m N 6 L$ gene expression in different organs. RNA gel blot of soybean total RNA $(20 \mu \mathrm{g})$ from leaves, stems, roots, and nodules of 4-weekold plants probed at high stringency with a riboprobe synthesized from the $3^{\prime}$-untranslated region of GmN6L. The lower panel shows the corresponding ethidium bromide-stained gel.
GmN6L protein, was detected in total soybean nodule protein from 4-week-old plants but not in uninfected roots from plants of the same age (Fig. 4). No signal was obtained using preimmune serum. The levels of GmN6L protein in roots at 1, 2, 3, and 4 weeks postinoculation with rhizobia were also analyzed. A strong signal was first detected 2 weeks after inoculation and then persisted throughout the time course examined (Fig. 4). No GmN6L protein was detected in control, mock-inoculated plants of the same ages or at 1 week postinoculation. The expression at 4 weeks postinoculation was limited to nodule tissue (Fig. 4).

\section{Cellular localization of GmN6L.}

Whole-mount immunodetection was used to localize the expression of GmN6L in mature nodule tissue. A strong signal was detected in cells of the infected zone of nodule tissues but not elsewhere (Fig. 5B). Control sections incubated with preimmune serum gave no signal (Fig. 5A).

Localization of GmN6L in subcellular fractions of nodules.

To verify that GmN6L is a PBM protein, we fractionated both root and nodule tissues to examine the subcellular localization of the GmN6L protein. As expected, no signal was detected in any of the root samples. In fractionated nodules, GmN6L protein was present in total soluble protein and at a high level in the symbiosome (Fig. 6). The symbiosome-localized GmN6L protein was most abundant in the soluble or peribacteroid space (PBS) fraction of symbiosomes, but a significant amount was also detected in the PBM fraction (Fig. 6). The presence of GmN6L protein in the total soluble fraction of nodules and the trace amounts of the protein in the total membrane fraction may represent contamination of these crude fractions by symbiosome proteins, because some symbiosomes are always broken when nodules are crushed to release their contents.

\section{DISCUSSION}

The predicted protein sequence of GmN6L contains a region that is almost identical to the $24 \mathrm{~N}$-terminal amino acids determined for PBM19 (Fig. 1). The single difference, a serine residue at position 20 of PBM19 versus a glycine in the predicted sequence of GmN6L, probably reflects a protein sequencing error since it occurs toward the end of the reliable peptide sequence. Interestingly, the PBM19 peptide sequence does not align with the $\mathrm{N}$ terminus of the predicted GmN6L protein. Instead, it begins 31 amino acids from the first methionine resi-

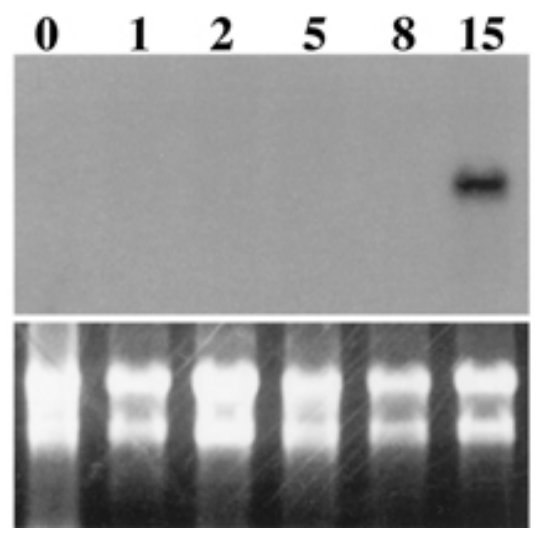

Fig. 3. GmN6L gene expression during early nodule development. RNA gel blot of soybean total RNA $(20 \mu \mathrm{g})$ from uninoculated roots and roots harvested $1,2,5,8$, and 15 days after inoculation with rhizobia. The blot was probed at high stringency with a riboprobe synthesized from the $3^{\prime}$ untranslated region of $G m N 6 L$. The lower panel shows the corresponding ethidium bromide-stained gel. 
due of GmN6L. The first 31 amino acids of GmN6L may represent a signal peptide that is cleaved during processing of the protein. Consistent with this idea is the observation that this segment of the protein is hydrophobic, like many known plant signal peptides (Chou 2001). The signal sequence prediction program, SignalP (Nielsen et al. 1999), predicted that this region has an $86 \%$ likelihood of being a signal peptide for the secretory pathway. The MtN6 protein has a similar hydrophobic leader sequence that is predicted to have a $98 \%$ likelihood of being a secretory signal peptide. Neither GmN6L nor MtN6 has identifiable endoplasmic reticulum retention sequences or vacuolar sorting signals. Apart from the first 31 residues, which are absent from the mature protein, GmN6L has no highly hydrophobic stretches of amino acids. Therefore, it is unlikely to be an integral membrane protein.

Southern blot analysis indicated the presence of a second sequence in the soybean genome with homology to GmN6L. This is also the case for many other genes in soybean, since the genome contains many duplicated regions (Shoemaker et al. 1996). Currently, we have no evidence that the GmN6L-related sequence is an active gene in soybean.

Northern blot analysis indicated the presence of a single, 1.5-kilobase GmN6L transcript in nodules but not other organs of soybean (Figs. 2 and 3). Using the extremely sensitive technique of real time RT-PCR, we were able to detect a very low level of GmN6L transcript in uninfected roots. There was no increase in $G m N 6 L$ transcript levels in roots during the early stages of infection. A significant increase in transcript abundance was first recorded 8 days after inoculation. However, GmN6L transcript abundance increased dramatically by day 15 , at which time it was more than 400 -fold higher than the basal level in roots (Table 1). At this stage, nitrogen-fixing nodules were present on roots. Thus, GmN6L exhibited the expression profile of a late nodulin gene. This was somewhat surprising, given that MtN6, the nearest homologue of GmN6L, is an early nodulin gene.

The results of Western blot analysis were consistent with those of Northern blots: GmN6L protein was first detected on nodulated roots 2 weeks after inoculation with rhizobia (Fig. 4). Separation of nodules from roots demonstrated that GmN6L protein was confined to the nodules (Fig. 4). Whole-mount immunolocalization of $\mathrm{GmN6L}$ revealed that the protein was restricted to the infected zone of mature root nodules (Fig. 5).

Subcellular fractionation followed by Western blot analysis indicated that GmN6L was present in soybean symbiosomes, not only bound to the PBM as found by Panter and colleagues (2000) but also as a soluble protein associated with symbiosomes (Fig. 6). The soluble form of GmN6L was liberated from symbiosomes by disruption of the PBM, suggesting that the protein may be present in the PBS, between the PBM and bacteroid membranes. The PBS is analogous to the extracellular space, being formed initially by endocytosis of the plasma membrane as rhizobia enter the plant cell. Therefore, the putative secretory signal sequence of GmN6L that we have identified could be involved in vesicle-mediated transport of GmN6L to

the PBS and PBM. Another hydrophilic protein, Nodulin 24, has been found on the PBM of soybean in the past (Cheon et al. 1994). Like GmN6L, Nodulin 24 has a hydrophobic leader sequence of 25 amino acid residues, which is cleaved from the mature protein (Cheon et al. 1994). The SignalP program predicted (99\% likelihood) that this N-terminal sequence targets Nodulin 24 to the secretory pathway.

Soybean $G m N 6 L$ was so-named because of its similarity to Medicago MtN6 (Fig. 1), which is also a nodulin (Gamas et al. 1996). However, the two genes differ in one important respect: MtN6 is an early nodulin, expressed in roots soon after inoculation by rhizobia, while $G m N 6 L$ is a late nodulin that is expressed at least 1 week after inoculation in mature, or nearly mature, nodules. It has been suggested that MtN6 may play an important role in the early stages of the symbiosis between $M$. truncatula and Sinorhizobium meliloti, perhaps in the infection process itself (Mathis et al. 1999). It is unlikely that $G m N 6 L$ plays such a role in soybean, because it is expressed late in nodule development. However, both MtN6 and GmN6L are expressed in close proximity to the bacterial symbionts, either along the infection route in Medicago (Mathis et al. 1999) or in the infected nodule cells in soybean. Therefore, N6L proteins may have a role in communication between the host and microsymbionts. Location of GmN6L protein in the symbiosomes of soybean, which contain the bacteroids, is consistent with this hypothesis. The difference in timing of GmN6L and MtN6 gene expression in soybean and Medicago, respectively, may reflect differences in the symbiotic relationships formed by these plants. Medicago produces indeterminate nodules, with a persistent meristem distal to the root, within which rhizobia continuously invade new plant cells in the so-called infection zone. Soybean, on the other hand, produces determinate nodules that have a central, transiently active meristem. Infection of nodule cortical cells occurs for a limited time in soybean, in contrast to the situation in Medicago. There are also differences between the rhizobia that infect soybean and Medicago:

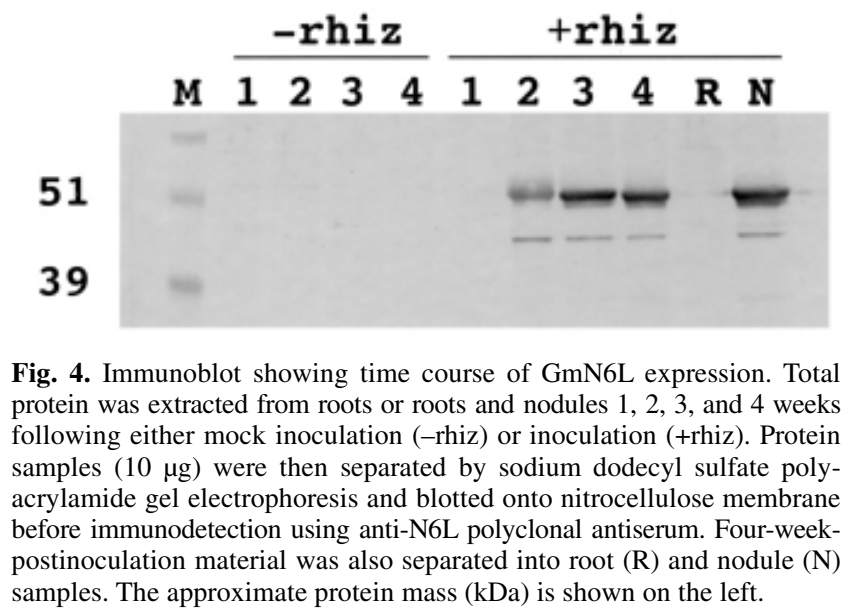

Table 1. Real time reverse-transcriptase polymerase chain reaction (RT-PCR) analysis of $G m N 6 L$ gene expression during early nodule development ${ }^{\mathrm{a}}$

\begin{tabular}{llcccccc}
\hline Gene & -RT & Day 0 & Day 1 & Day 3 & Day 5 & Day 8 & Day 15 \\
\hline GmUBI & N.D. & $20.0 \pm 0.1$ & $20.0 \pm 0.1$ & $19.2 \pm 0.2$ & $20.3 \pm 0.1$ & $20.4 \pm 0.3$ & $20.5 \pm 0.2$ \\
GmN6L & N.D. & $36.3 \pm 1.8$ & $35.5 \pm 2.0$ & $33.8 \pm 0.7$ & $35.9 \pm 1.4$ & $32.9 \pm 0.4$ & $24.2 \pm 0.4$ \\
Ration & & 1 & 1.7 & 1.8 & 0.5 & 8.7 & 448.8 \\
\hline
\end{tabular}

${ }^{\text {a }}$ Real time RT-PCR was used to compare the level of GmN6L gene expression in root samples collected before inoculation (Day 0) with the levels of GmN6L gene expression in roots harvested $1,2,5,8$, and 15 days after inoculation with rhizobia. The table shows average $\mathrm{C}_{\mathrm{T}}($ threshold cycle) values $( \pm$ standard deviation) from three replicates at each time point for both $G m N 6 L$ and $U B I$, a constitutively expressed gene. A reaction containing no reverse transcriptase was used as a negative control (-RT). Expression of GmN6L was normalized against the level of $U B I$ expression for each time point, and normalized expression values were compared with the mock-inoculated root sample $\left(\mathrm{Ratio}_{\mathrm{n}}\right)$. N.D. $=$ Not detectable. 
Bradyrhizobium japonicum is slow growing in culture, while $S$. meliloti is fast growing. Whether or not these differences influence the roles of GmN6L and MtN6 in soybean and Medicago nodules, respectively, remains to be seen.

Consistent with a role for GmN6L in communication between symbiotic partners is the homology between GmN6L and the N-terminal domain of the FluG protein of Aspergillus nidulans (Fig. 1). FluG is believed to produce a small molecule that acts as a diffusible extracellular signal during the initiation of conidiation (Lee and Adams 1994). The FluG protein has, in addition to an N6L domain, a second domain with homology to glutamine synthetase I (GSI), which alone is sufficient for the production of an unidentified extracellular signal molecule (D'Souza et al. 2001). The recent identification of a GSI-like gene in Medicago raises the interesting possibility that MtN6 is also able to interact with a GSI-like protein (Mathis et al. 2000) to produce some type of signal molecule. Another possibility is that MtN6 and GmN6L proteins are able to interact with two-domain FluG homologues. The Arabidopsis homologue of MtN6 (CAB64221.1) is predicted to have both an N6L and a GSI-like domain, and similar genes are reported to exist in Medicago (Mathis et al. 2000).

Whether or not N6L proteins are involved in the production of a signal molecule may be determined through metabolite profiling of transgenic plants that under- or over-express these proteins. An understanding of the enzymatic properties of the GSI-like domain, alone or as part of a full FluG homologue, could also help to clarify the functions of N6L proteins.

\section{MATERIALS AND METHODS}

\section{Plant culture.}

Soybean seeds (G. max cv. Stevens) were inoculated with $B$. japonicum USDA110 and grown as described by Panter and colleagues (2000).

\section{PCR cloning.}

Two primers, PBM19f1 and PBM19f2 (using International Union of Pure and Applied Chemistry codes for DNA: 5'ATGGAYTTYWSNGARYTNMGNAAAGC-3' and 5'-ATGGAYTTYWSNGARYTNMGNAAGGC-3') were designed on the basis of the PBM19 peptide sequence MDFSELRK. These differed by a single base only (underlined) but allowed maximum homology between the $3^{\prime}$ end of the primers and the possible target sequences, while also reducing primer redundancy by a factor of two. PCR reactions ( $3^{\prime}$-RACE) were performed with each of these primers together with a universal reverse primer (URP) (5'-TTGGATCC(T) $\left.)_{18^{-}} 3^{\prime}\right)$, with soybean nodule firststrand cDNA as a template. $\mathrm{PCR}$ reaction conditions were as follows: 35 cycles of $20 \mathrm{~s}$ at $94^{\circ} \mathrm{C}, 30 \mathrm{~s}$ at $45^{\circ} \mathrm{C}$, and $3 \mathrm{~min}$ at $72^{\circ} \mathrm{C}$. A specific 1,400 -base pair (bp) fragment was amplified by the PBM19f1/Universal primer combination. This fragment was gel-purified and reamplified, before being cloned and sequenced with an ABI Prism 377 sequencer (Applied Biosystems, Foster City, CA, U.S.A.). The sequence of this clone was used to design a gene-specific primer (5'-CTTCTCTTGAAGGATAGAGAGG-3'), which was then used to obtain the entire PBM19 coding sequence via 5'-RACE. The Marathon RACE kit (Clontech, Palo Alto, CA, U.S.A.) was used for this purpose. The sequences of three independent clones were compared to ensure the absence of any errors resulting from PCR amplification.

\section{Southern analysis.}

Genomic DNA was extracted from soybean leaves (Dellaporta et al. 1983) and the subsequent steps of digestion, electrophoresis, blotting, and hybridization were performed as described by Ausubel and colleagues (1994). Probes (from bases 1,128 to 1,356 of $G m N 6 L$ ) were prepared with the rediprime kit (Amersham Pharmacia Biotech, Little Chalfront, U.K.) and were chloroform-extracted to decrease nonspecific background. Blots were exposed to X-ray film, which was developed in the standard manner.

\section{RNA gel blot analysis.}

Total RNA was extracted from soybean organs according to the protocol of Logemann and colleagues (1987). Electrophoresis, blotting, and hybridization were performed as described previously (Dolferus et al. 1994). Total RNA from leaves, stems, roots, and nodules was hybridized with an antisense riboprobe produced from the $3^{\prime}$-UTR (bases 1,061 to $1,463)$ of $G m N 6 L$.

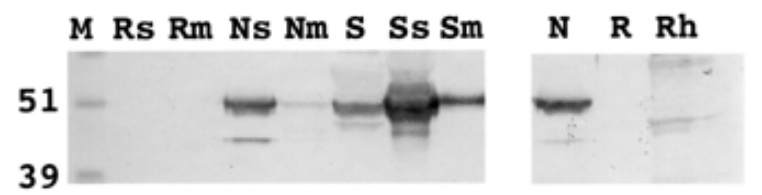

Fig. 6. Subcellular localization of GmN6L protein. Immunoblot of subcellular fractions of 4-week-old soybean roots and nodules. Rs and Rm are $10 \mu \mathrm{g}$ of protein from root soluble and membrane fractions, respectively. Ns and $\mathrm{Nm}$ are $10 \mu \mathrm{g}$ of protein from crude nodule soluble and membrane fractions, respectively. $\mathrm{S}$ corresponds to $10 \mu \mathrm{g}$ of total symbiosome proteins, Ss to $10 \mu \mathrm{g}$ of soluble symbiosome proteins, and Sm to $5 \mu \mathrm{g}$ of peribacteroid membrane proteins. The last three lanes are $10 \mu \mathrm{g}$ of total nodule $(\mathrm{N})$, total root $(\mathrm{R})$, and total rhizobial protein $(\mathrm{Rh})$. Approximate mass $(\mathrm{kDa})$ is shown on the left.

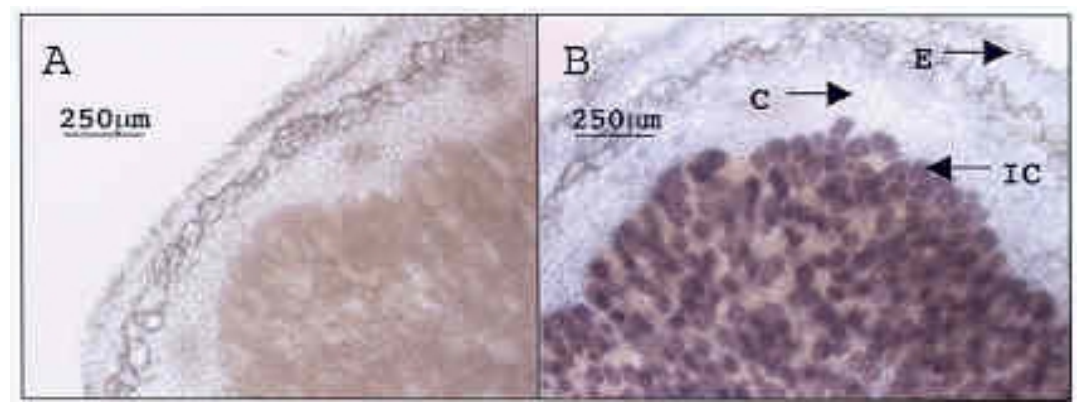

Fig. 5. Tissue localization of GmN6L protein. Sections of 4 -week-old soybean nodules reacted with $\mathbf{A}$, preimmune serum ( $\times 40$ magnification) or $\mathbf{B}$, antiN6L polyclonal antiserum ( $\times 40$ magnification). Antibody-specific staining is visible as purple coloration. B, Staining was predominantly observed in large, infected cells (IC) of the infected region of the nodule. Epidermal cells (E) and the noninfected cortical cells (C) did not stain. A, No staining resulted from the use of preimmune serum. 


\section{Real time RT-PCR.}

Total RNA $(10 \mu \mathrm{g})$ was used to prepare mRNA using the Qiagen Oligotex mRNA kit (Qiagen, Hilden, Germany). Approximately $10 \mathrm{ng}$ of mRNA was then reverse-transcribed with Moloney murine leukemia virus (MMLV) reverse transcriptase (Promega, Madison, WI, U.S.A.) and the URP in a reaction volume of $50 \mu \mathrm{l}$, to generate first-strand cDNA. Real time RTPCR was performed with $2 \mu$ of a $1 / 10$ dilution of the firststrand cDNA reaction and the SYBR Green reagent (Perkin Elmer, Norwalk, CA, U.S.A.), in a $25-\mu$ l reaction volume, on a Perkin Elmer Geneamp 5700 machine. Primers were designed to the 3'-UTR of GmN6L (GmN6L3'f: 5'-CCTGAAACCTTCTACCTAGGTGC-3' and GmN6L'3'r: 5'-GTGGGTTCGTGTTCTTCCAGG-3'). These primers amplified a single product of $228 \mathrm{bp}$, as shown by the melting temperature of the amplicons and gel electrophoresis. Likewise, ubiquitin primers (GmUf: 5'-GTGTAATGTTGGATGTGTTCCC-3' and GmUr: 5'-ACACATTGAGTTCAACACAAACCG-3') were designed from the G. max ubiquitin gene (UBI; GenBank accession no. X1325). Reactions without template or that lacked reverse transcriptase were included as negative controls. GmN6L data were normalized to $U B I$ and then compared according to the formula:

$$
\begin{aligned}
& \mathrm{nC}_{\mathrm{T}}=\mathrm{C}_{\mathrm{T}} G m N 6 L-\mathrm{C}_{\mathrm{T}} G m U B I \\
& \Delta \mathrm{C}_{\mathrm{T}}=\mathrm{nC}_{\mathrm{T}} x-\mathrm{nC}_{\mathrm{T}} y \\
& \text { Ratio }_{\mathrm{n}}=2^{-\Delta \mathrm{CT}}
\end{aligned}
$$

$\mathrm{C}_{\mathrm{T}}$ (threshold cycle) is the fractional cycle number at which the amount of amplified target reaches a fixed threshold $(0.1$ units), $\mathrm{nC}_{\mathrm{T}}$ is the normalized $\mathrm{C}_{\mathrm{T}}$ value, $\Delta \mathrm{C}_{\mathrm{T}}$ is the difference in normalized $\mathrm{C}_{\mathrm{T}}$ values at times $x$ and $y$, and Ratio ${ }_{\mathrm{n}}$ is the ratio of the normalized gene activity at time $x$ compared with $y$, assuming that the amplification efficiency of both reactions is $100 \%$.

\section{Westerns blots.}

To obtain an anti-N6L antibody, a N6L EST from Lotus japonicus (GenBank accession no. AW719864) was expressed in Escherichia coli fused to a histidine tag (pQE30; Qiagen) and purified with nickel affinity columns (Qiagen). Purified protein was then injected into rabbits (Pineda Antikörper Service, Berlin, Germany) and polyclonal antisera were collected 61 and 90 days after immunization. Total protein was extracted from soybean nodules or roots by grinding tissue in liquid nitrogen and dissolving the resulting powder in Tris-buffered saline (TBS) $(10 \mathrm{mM}$ Tris, $\mathrm{pH} 7.4 ; 100 \mathrm{mM} \mathrm{NaCl}$ ) with $1 \%$ sodium dodecyl sulfate (SDS). Protein concentration was determined by using the BioRad protein assay kit (Bio-Rad, Veenendaal, The Netherlands) as per the manufacturer's instructions. Novex precast gels (Invitrogen, Groningen, The Netherlands) were used to separate the proteins before electroblotting onto nitrocellulose membrane (Ausubel et al. 1994). Membranes were blocked with 1× TBS $/ 5 \%$ nonfat milk for $1 \mathrm{~h}$, before the addition of the primary antibody $(1 / 2,000$ dilution). Membranes were washed four times for $10 \mathrm{~min}$ in $1 \times \mathrm{TBS} / 0.1 \%$ Tween (TBST), before the addition of an anti-rabbit alkaline phosphatase-conjugated antibody, 1/5,000 dilution (Promega). Membranes were rewashed (TBST) and an alkaline phosphatase color reaction performed using Nitro blue tetrazolium (NBT) and 5-bromo-chloro-3-indolyl-phosphate, toluidine salt (BCIP) (Roche Diagnostics, Mannheim, Germany), according to the manufacturer's instructions.

\section{Whole-mount immunodetection of GmN6L in nodules.}

Soybean nodules were set in 5\% agarose and cut into $100-\mu \mathrm{M}$ thick sections with a vibratome (Leica, Bensheim, Germany). Sections were placed in FAA fixative (3.7\% formaldehyde, $50 \%$ ethanol, $5 \%$ acetic acid) and left at $4{ }^{\circ} \mathrm{C}$ overnight. Sections were then washed for $5 \mathrm{~min}$ in each of the following:
$50 \%$ TBST $/ 50 \%$ methanol, methanol twice, ethanol three times, methanol twice, and 50\% TBST/50\% methanol, before being refixed for $30 \mathrm{~min}$. Sections were blocked in blocking buffer (5\% fat-free milk powder, $1 \times \mathrm{TBST}$ ) at $4{ }^{\circ} \mathrm{C}$ overnight and then incubated with primary antibody $(1 / 1,000$ dilution) in blocking buffer for $1 \mathrm{~h}$ at room temperature. Six 10-min washes in $1 \times$ TBST were performed before incubation with secondary antibody (goat anti-rabbit alkaline phosphatase Fab fragment, $1 / 5,000$ dilution; Promega) in blocking buffer. Sections were rewashed as described above, before color reaction was performed. Sections were placed in stop buffer $(1 \times$ TBST, $\mathrm{pH}$ $5.5)$ for $10 \mathrm{~min}$ to terminate color reaction and cleared in glycerol overnight at $4^{\circ} \mathrm{C}$.

\section{Subcellular fractionation.}

Total nodule protein was obtained by first grinding the nodule tissue in TBS with $1 \%$ SDS in a prechilled pestle and then centrifuging at $10,000 \times g$ at $4^{\circ} \mathrm{C}$ for $5 \mathrm{~min}$ in a benchtop centrifuge to remove insoluble matter. Total nodule soluble and microsomal proteins of soybean nodules were isolated using the method of Fedorova (Fedorova et al. 1999). PBM and PBS fractions were prepared as described by Panter and colleagues (2000).

\section{ACKNOWLEDGMENTS}

We would like to thank S. Freund for excellent technical assistance. This work was funded in part by the Max Planck Society and the Australian Research Council. B. Trevaskis was supported by an Alexander von Humboldt fellowship.

\section{LITERATURE CITED}

Allaway, D., Lodwig, E. M., Crompton, L. A., Wood, M., Parsons, R., Wheeler, T. R., and Poole, P. S. 2000. Identification of alanine dehydrogenase and its role in mixed secretion of ammonium and alanine by pea bacteroids. Mol. Microbiol. 36:508-515.

Altschul, S. F., Gish, W., Miller, W., Myers, E. W., and Lipman, D. J. 1990. Basic local alignment search tool. J. Mol. Biol. 215:403-410.

Ausubel, F. M., Brenton, R., Kingston, R. E., Moore, D. D., Siedman, J. G., Smyth, J. A., and Struhl, K. N. Y. 1994. Current Protocols in Molecular Biology. J. Wiley \& Sons, New York.

Bergersen, F. J., and Turner, G. L. 1990. Bacteroids from soybean root nodules: Respiration and $\mathrm{N}_{2}$ fixation in flow chamber reactions with oxyleghemoglobin. Proc. R. Soc. Lond. Ser. B. Biol. Sci. 238:295320.

Cheon, C. I., Hong, Z., and Verma, D. P. 1994. Nodulin-24 follows a novel pathway for integration into the peribacteroid membrane in soybean root nodules. J. Biol. Chem. 269:6598-6602.

Chou, K. C. 2001. Prediction of protein signal sequences and their cleavage sites. Proteins 42:136-139.

Dellaporta, S. L., Wood, J., and Hicks, J. B. 1983. A plant DNA minipreparation, version II. Plant Mol. Biol. Rep. 1:19-21.

Dolferus, R., Jacobs, M., Peacock, W. J., and Dennis, E. S. 1994. Differential interactions of promoter elements in stress responses of the Arabidopsis Adh gene. Plant Physiol. 105:1075-1087.

D'Souza, C. A., Lee, B. N., and Adams, T. H. 2001. Characterization of the role of the FluG protein in Aspergillus nidulans. Genetics 158: 1027-1036.

Fedorova, E., Thomson, R., Whitehead, L. F., Maudoux, O., Udvardi, M. K., and Day, D. A. 1999. Localization of H+-ATPases in soybean root nodules. Planta 209:25-32.

Gamas, P., Niebel, F. de C., Lescure, N., and Cullimore, J. V. 1996. Use of a subtractive hybridization approach to identify new Medicago truncatula genes induced during root nodule development. Mol. PlantMicrobe Interact. 9:233-242.

Lee, B. N., and Adams, T. H. 1994. The Aspergillus nidulans FluG gene is required for production of an extracellular developmental signal and is related to prokaryotic glutamine synthetase I. Genes Dev. 8:641-651.

Logemann, J., Schell, J., Willmitzer, L., and Frommer, W. B. 1987. Improved method for the isolation of RNA from plant tissues. Anal. Biochem. 163:16-20.

Mathis, R., Grosjean, C., de Billy, F., Huguet, T., and Gamas, P. 1999. The early nodulin gene MtN6 is a novel marker for events preceding 
infection of Medicago truncatula roots by Sinorhizobium meliloti. Mol. Plant-Microbe Interact. 12:544-555.

Mathis, R., Gamas, P., Meyer, Y., and Cullimore, J. V. 2000. The presence of GSI-like genes in higher plants: Support for the paralogous evolution of GSI and GSII genes. J. Mol. Evol. 50:116-122.

Nielsen, H., Brunak, S., and von Heijne, G. 1999. Machine learning approaches for the prediction of signal peptides and other protein sorting signals. Protein Eng. 12:3-9.

Panter, S., Thomson, R., de Bruxelles, G., Laver, D., Trevaskis, B., and Udvardi, M. 2000. Identification with proteomics of novel proteins associated with the peribacteroid membrane of soybean root nodules. Mol. Plant-Microbe Interact. 13:325-333.
Pearson, W. R., and Lipman, D. J. 1988. Improved tools for biological sequence comparison. Proc. Natl. Acad. Sci. U.S.A. 85:2444-2448.

Shoemaker, R. C., Polzin, K., Labate, L., Specht, J., Brummer, E. C., Olson, T., Young, N., Concibido, V., Wilcox, J., Tamulonis, J. P., Kochert, G., and Boerma, H. R. 1996. Genome duplication in soybean (Glycine subgenus soja). Genetics 144:329-338.

Stougaard, J. 2000. Regulators and regulation of legume root nodule development. Plant Physiol. 124:531-540.

Udvardi, M. K., and Day, D. A. 1997. Metabolite transport across symbiotic membranes of legume nodules. Annu. Rev. Plant Physiol. Plant Mol. Biol. 48:493-523. 